\title{
An isoform of AIF1 involved in breast cancer
}

\author{
Ferial Amira Slim ${ }^{1,2+}$, Geneviève Ouellette ${ }^{1 \dagger}$, Kaoutar Ennour-Idrissi ${ }^{1,3}$, Simon Jacob ${ }^{1,4}$, Caroline Diorio ${ }^{1,3}$ \\ and Francine Durocher ${ }^{1,2^{*}}$
}

\begin{abstract}
Background: Inflammation is a major player in breast cancer (BC) progression. Allograft-inflammatory factor-1 (AIF1) is a crucial mediator in the inflammatory response. AIF1 reportedly plays a role in BC, but the mechanism remains to be elucidated. We identified two AIF1 isoforms, AIF1V1 and AIF1V3, which were differentially expressed between affected and unaffected sisters from families with high risk of BC with no deleterious BRCA1/BRCA2 mutations (BRCAX). We investigated potential functions of AIFv1/V3 in BC of varying severity and breast adipose tissue by evaluating their expression, and association with metabolic and clinical parameters of $B C$ patients.

Methods: AIF1V1/V3 expression was determined in BC tissues and cell lines using quantitative real-time PCR. Potential roles and mechanisms were examined in the microenvironment (fibroblasts, adipose tissue, monocytes and macrophages), inflammatory response (cell reaction in BC subgroups), and metabolism [treatment with docosahexaenoic acid (DHA)]. Association of AlF1 transcript expression with clinical factors was determined by Spearman's rank correlation. Bioinformatics analyses were performed to characterize transcripts.
\end{abstract}

Results: AIF1V1/V3 were mostly expressed in the less severe BC samples, and their expression appeared to originate from the tumor microenvironment. AIF1 isoforms had different expression rates and sources in breast adipose tissue; lymphocytes mostly expressed AIFIV 1 while activated macrophages mainly expressed AIF1V3. Bioinformatics analysis revealed major structural differences suggesting distinct functions in $B C$ progression. Lymphocytes were the most infiltrating cells in breast tumors and their number correlated with AIFIV1 adipose expression. Furthermore, DHA supplementation significantly lowered the expression of AIF1 isoforms in BRCAX cell lines. Finally, the expression of AIF1 isoforms in $\mathrm{BC}$ and breast adipose tissue correlated with clinical parameters of $\mathrm{BC}$ patients.

Conclusions: Results strongly suggest that AIF1V1 as much as AIF1V3 play a major role in the crosstalk between BC and infiltrating immune cells mediating tumor progression, implying their high potential as target molecules for BC diagnostic, prognostication and treatment.

Keywords: Breast cancer, AIF1, Isoforms, Breast tumors, Tumor microenvironment, Inflammation

\section{Background}

According to the latest statistics, females are more likely to develop breast cancer $(\mathrm{BC})$ than any other cancer. It is the most commonly diagnosed cancer in more and less developed regions, and the second most common cause of cancer death in women worldwide [1]. BC initiation

\footnotetext{
*Correspondence: francine.durocher@crchudequebec.ulaval.ca

${ }^{\dagger}$ Ferial Amira Slim and Geneviève Ouellette are equal first authors

${ }^{1} \mathrm{CHU}$ de Québec Research Centre and Cancer Research Centre-Laval

University, 2705 Laurier Boulevard, Quebec City, QC G1V 4G2, Canada

Full list of author information is available at the end of the article
}

(c) The Author(s) 2018. This article is distributed under the terms of the Creative Commons Attribution 4.0 International License (http://creativecommons.org/licenses/by/4.0/), which permits unrestricted use, distribution, and reproduction in any medium, provided you give appropriate credit to the original author(s) and the source, provide a link to the Creative Commons license, and indicate if changes were made. The Creative Commons Public Domain Dedication waiver (http://creativecommons.org/ publicdomain/zero/1.0/) applies to the data made available in this article, unless otherwise stated. 
and progression are related to many factors including inflammatory factors which may be implicated in the development of therapy resistance [2].

During tumor development, the immune system can either recognize and destroy tumors or promote their growth. This process is called immunoediting [3]. Many studies have shown that the immune system is a major player in the cancer cell/tumor microenvironment crosstalk. Tumor-infiltrating immune cells are frequently observed and associated with cancer prognosis [4-7]. Several clinical studies have evaluated the prognostic significance of tumor-infiltrating lymphocytes (TILs) and tumor-associated macrophages (TAMs) in BC $[8,9]$. Furthermore, inflammatory cytokines, such as interleukin 6 (IL-6) and tumor necrosis factor alpha (TNF $\alpha$ ), have been shown to play important roles in the progression of BC [10].

Allograft inflammatory factor-1 (AIF1) was first identified in rat cardiac allografts undergoing chronic rejection [11]. In humans, the AIF1 phylogenetically conserved gene is encoded within the major histocompatibility complex class III region on chromosome $6 \mathrm{p} 21.3$, which is known to harbor clusters of genes involved in inflammatory responses such as TNF $\alpha$ and nuclear factor-kappa B (NF-KB) [12]. Three splice isoforms have been identified including the AIF1 splice variant 3 (AIF1v3) considered to be the "wild-type" and the largest isoform encoding a 143-amino acid hydrophilic polypeptide of $17 \mathrm{kDa}$.

The function of AIF1 is not entirely known, but it has been found to be mainly expressed by immunocytes and closely associated with inflammatory diseases [13], obesity $[14,15]$, diabetes $[16-18]$ and cancers $[19,20]$. It is a well-known central mediator of inflammation by regulating the expression of inflammatory mediators such as cytokines, chemokines and inducible nitric oxide synthase $[21,22]$.

Indeed, numerous studies have demonstrated that AIF1 is involved in inflammatory responses, auto-immune diseases, reproductive immunity as well as immune activation and macrophage function [13]. AIF1 can increase IL-6, IL-10, and IL-12 production in the RAW 264.7 macrophage cell line stimulated with lipopolysaccharides [22]. In addition to immunomodulating functions, a recent report indicates that AIF1 may regulate several important cell adhesion molecules [23].

Previous studies have reported an increase in AIF1 expression in malignancies and suggest that it may have a significant role in cancer progression [20, 24]. Furthermore, AIF1v3 may promote $\mathrm{BC}$ proliferation through activation of the NF- $\mathrm{kB} / \mathrm{cyclin} \mathrm{D} 1$ pathway [25]. Additional studies have shown that AIF1v3 may promote BC cell migration via the upregulation of TNF $\alpha$-mediated activation of the p38-MAPK signaling pathway [26] and may increase the resistance of $\mathrm{BC}$ cells to cisplatin [27].

However, whether other AIF1 isoforms are also involved in $\mathrm{BC}$ development and progression has not yet been reported. The role and expression of AIF1 isoforms in the tumor microenvironment are also not known.

The present study aims to explore potential functions of two AIF1 isoforms (AIFv1 and AIF1v3) in breast tumors of varying severity and breast adipose tissue by evaluating their expression and relationship to metabolic and clinical parameters of $\mathrm{BC}$ patients. To better understand the association linking inflammation, AIF1 and BC progression, the relationship between components of the tumor inflammatory cell infiltrate and AIF1 expression in breast adipose tissue was examined in histopathological breast tumor sections. The effect of omega- 3 fatty acids (FA) on AIF1 isoform expression was evaluated in lymphoblastoid cell lines (LCLs) cell lines to determine their potential functions.

Although AIF1 has been studied previously in other health conditions such as inflammatory diseases, to our knowledge, this is the first evaluating the AIF1v1 isoform in the context of $\mathrm{BC}$.

\section{Methods \\ Patients and study design \\ BRCAX population: AIF1}

As part of a previous study, 115 women issued from BRCA1, BRCA2 and non-BRCA1/2 (BRCAX) families with high risk of $\mathrm{BC}$ were selected for transcriptome analysis. Selection of study population is described elsewhere [28]. Our BRCAX cohort comprised 16 pairs of BC affected and unaffected sisters issued from BRCAX families (age $60 \pm 25$ years). Using this cohort, we identified significantly and differentially expressed transcripts of the AIF1 gene.

We characterized transcriptional profiles in French Canadian families with high risk of breast and ovarian cancer using RNA-sequencing methodology. RNA was isolated from immortalized LCLs of 115 women (affected and unaffected) issued from BRCA1, BRCA2 and BRCAX families. Statistical analyses were carried out using the $\mathrm{R}$ Package v3.3 as previously described [28]. Briefly, onefactor analysis of variance (ANOVA), Bonferroni correction and Scheffé's test were performed to identify specific transcripts associated with the BRCAX subgroup. Overall, 190 transcripts were identified within BRCAX individuals, and two AIF1 transcripts, in particular, were significantly and differentially expressed between the 16 pairs of affected and unaffected sisters. All individuals provided their written informed consent for the banking of their genetic material (Dr. J. Simard, director). 


\section{$B C$ population and clinical evaluation}

Our study population included pre-and postmenopausal women with $\mathrm{BC}$ that were prospectively recruited between January 2011 and May 2012, at the DeschênesFabia Center for Breast Diseases in Quebec City, Canada, a BC reference center. Briefly, women were eligible if they were not older than 70 years, were not pregnant, had no previous diagnosis of cancer other than nonmelanoma skin cancer, never had any breast surgery, never took a selective estrogen receptor modulator, and had not received any treatment before BC surgery. Clinical data (data collection described previously [29]), and patient characteristics are shown in Table 1. Cohort 1, comprising thirteen women (age 48.3 \pm 9.3 years, BMI $28.2 \pm 6.8 \mathrm{~kg} / \mathrm{m}^{2}$ ), was used to evaluate AIF1 expression in breast tumors of varying severity. The expression of AIF1 transcripts in breast adipose tissue was measured in cohort 2 comprising 74 women (age $51.9 \pm 8.5$ years, BMI $26.2 \pm 5.6 \mathrm{~kg} / \mathrm{m}^{2}$ ). All participants provided written informed consent. The study protocol was reviewed and approved by the Research Ethics Committee of the CHU de Quebec Research Center-Laval University, in accordance with their relevant guidelines and regulations.

Table 1 Description of the cohorts

\begin{tabular}{|c|c|c|}
\hline Variables & Cohort $1 \mathrm{~N}=13$ & Cohort $2 \mathrm{~N}=74$ \\
\hline Age $^{a}$ (years) & $48.3 \pm 9.3$ & $51.9 \pm 8.5$ \\
\hline $\mathrm{BMI}^{\mathrm{a}}\left(\mathrm{kg} / \mathrm{m}^{2}\right)$ & $28.2 \pm 6.8$ & $26.2 \pm 5.6$ \\
\hline \multicolumn{3}{|l|}{ Menopausal status ${ }^{b}$} \\
\hline Premenopause & $8(61.54)$ & $17(22.97)$ \\
\hline Postmenopause & $5(38.46)$ & $57(77.03)$ \\
\hline \multicolumn{3}{|l|}{ ER status $^{\mathrm{b}}$} \\
\hline Positive & $8(61.54)$ & $69(93.24)$ \\
\hline Negative & $5(38.46)$ & $5(6.76)$ \\
\hline \multicolumn{3}{|l|}{ PR status ${ }^{b}$} \\
\hline Positive & $7(53.85)$ & $65(87.84)$ \\
\hline Negative & $6(46.15)$ & $9(12.16)$ \\
\hline \multicolumn{3}{|l|}{ HER2 status ${ }^{\mathrm{b}}$} \\
\hline Positive & $4(30.77)$ & $8(10.81)$ \\
\hline Negative & $5(38.46)$ & $54(72.97)$ \\
\hline Not assessable & $4(30.77)$ & $12(16.22)$ \\
\hline \multicolumn{3}{|l|}{$\mathrm{BC}^{\mathrm{b}}$} \\
\hline DCIS & $4(30.77)$ & $5(6.76)$ \\
\hline \multicolumn{3}{|l|}{ IDC } \\
\hline Luminal & $4(30.77)$ & $65(87.84)$ \\
\hline HER2+ & $2(15.38)$ & $1(1.35)$ \\
\hline Triple negative & $3(23.08)$ & $1(1.35)$ \\
\hline Unclassified & - & $2(2.70)$ \\
\hline
\end{tabular}

$B M I$ body mass index, $E R$ estrogen receptor, $P R$ progesterone receptor, $H E R 2$ human epidermal growth factor receptor $2, B C$ breast cancer, $D C I S$ ductal carcinoma in situ, IDC invasive ductal carcinoma

Data presented as ${ }^{a}$ mean $\pm S D,{ }^{b}$ number of individuals (\%)

\section{Cell culture}

Human cancer cell lines MCF7, ZR75, SKBR3, MDAMB-231, BT20, OV90, OVCAR-3, LNCaP, HEK293, the non-cancerous human cell line MCF10A and the THP-1 monocytic human cell line were purchased from the American Type Culture Collection (ATCC). Adipocytes were isolated from mammary and abdominal (subcutaneous and omental) adipose tissue of women undergoing bariatric surgery. Fibroblasts were isolated from the mammary adipose tissue of BC patients. All cell lines except for THP-1, were subcultured according to ATCC recommendations.

THP-1 monocyte culturing and macrophage differentiation were carried out using Roswell Park Memorial Institute medium (RPMI 1640, Invitrogen) supplemented with $10 \%$ heat-inactivated FBS and $1 \%$ penicillin/streptomycin. Fibroblasts were maintained in Eagle's Minimum Essential Medium supplemented with 15\% FBS, 1\% glutamine and $1 \%$ penicillin/streptomycin.

\section{RNA isolation}

RNA was extracted from monocytes, macrophages, adipocytes and fibroblasts using the miniRNeasy minikit (Qiagen). Total RNA from BRCA LCLs was extracted using TRI Reagent (Molecular Research Center Inc., Cincinnati, OH, USA) according to manufacturer's instructions [29]. RNA was also obtained from human cancer cell lines (MCF7, ZR75, SKBR3, MDA-MB-231, BT20, OV90, OVCAR-3, LNCaP, HEK293) as well as BRCA LCLs. Samples of formalin-fixed and paraffin-embedded (FFPE) breast adipose tissue from BC patients were extracted with miRNeasy (FFPE) kit (Qiagen). BC samples of varying severity: DCIS and molecular subtypes of IDC, i.e. Luminal A/B (ER+ and/or PR+), HER2+ (ER-/ $\mathrm{PR}-/ \mathrm{HER} 2+$ ) and triple-negative tumors (ER-/PR-/ HER2-) were extracted using RNeasy FFPE kit (Qiagen). RNA was reverse-transcribed using the Superscript IV kit (Invitrogen). Non-FFPE samples were purified using the QIAquick PCR Purification Kit (Qiagen).

\section{Monocyte culture and macrophage differentiation}

Differentiation of human monocytic THP-1 cells into macrophages was performed according to Genin et al. [30]. Briefly, THP-1 monocytes were maintained in culture in RPMI medium and differentiated into macrophages following a $24 \mathrm{~h}$ incubation with $150 \mathrm{nM}$ phorbol 12-myristate 13-acetate (PMA) followed by a $24 \mathrm{~h}$ incubation in RPMI medium. Macrophages were polarized to M1 macrophages by incubation for $24 \mathrm{~h}$ with $20 \mathrm{ng} / \mathrm{ml}$ of IFN- $\gamma$ (Peprotech) and $10 \mathrm{pg} / \mathrm{ml}$ of LPS (Sigma). For M2 polarization, macrophages were 
incubated with $20 \mathrm{ng} / \mathrm{ml}$ of IL-4 (Peprotech) and $20 \mathrm{ng} /$ $\mathrm{ml}$ of IL-13 (Peprotech) for $72 \mathrm{~h}$. Cells were then collected using QIAzol and RNA was extracted as described.

\section{EPA/DHA treatment}

BRCAX LCLs were cultured in RPMI medium supplemented with $10 \%$ FBS and $1 \%$ penicillin/streptomycin in equally seeded 6-well plates, followed by incubation with either ethanol or various concentrations of eicosapentaenoic acid (EPA), docosahexaenoic acid (DHA), or a mixture of EPA: DHA (Sigma-Aldrich) for 24, 48 and $72 \mathrm{~h}$ ([EPA or DHA] $=0,1,5,10,20,40,50 \mu \mathrm{M}$ and [EPA:DHA] $=5: 5,15: 5$ and 5:15 $\mu \mathrm{M})$. Each omega-3 FA was dissolved by serially diluting in ethanol as recommended by the manufacturer and then added to media. RNA was then extracted, reverse-transcribed and purified. AIF1 expression was quantified by qRT-PCR as described in the following section. All experiments were performed in triplicate, and similar results were obtained from each experiment.

\section{Quantitative real-time PCR ( $q R T-P C R)$}

Oligoprimer pairs were designed by GeneTool 2.0 software (Biotools Inc, Edmonton, $\mathrm{AB}, \mathrm{CA}$ ) and their specificity was verified by blast in the GenBank database. The synthesis was performed by IDT (Integrated DNA Technology, Coralville, IA, USA) (see Additional file 1: Table S1).

cDNA corresponding to $20 \mathrm{ng}$ of total RNA was used to perform fluorescent-based Realtime PCR quantification using the LightCycler 480 (Roche Diagnostics, Mannheim, DE). LightCycler 480 SYBRGreen I Master reagent (Roche Diagnostics, Indianapolis, IN, USA) was used with $2 \%$ DMSO, as described by the manufacturer. PCR was carried out using the following parameters: 45 cycles, denaturation at $98^{\circ} \mathrm{C}$ for $10 \mathrm{~s}$, annealing at $60^{\circ} \mathrm{C}$ for $10 \mathrm{~s}$, elongation at $72{ }^{\circ} \mathrm{C}$ for $10 \mathrm{~s}$ and then $72{ }^{\circ} \mathrm{C}$ for $5 \mathrm{~s}$ (reading). A melting curve analysis was performed to assess non-specific signals. Relative quantity was calculated using the fit point method and by applying the delta Ct method [31]. Normalization was done using reference genes that have shown stable expression levels from embryonic life through adulthood in various tissues [32]. ATP synthase subunit O (ATP5O), glucose-6-phosphate dehydrogenase (G6PD), hypoxanthine guanine phosphoribosyl transferase 1 (HPRT1) and glyceraldehyde3-phosphate dehydrogenase (GAPDH) were used as reference genes for analysis in the breast adipose tissue. HPRT1 and GAPDH were used as reference genes for analysis in breast tumors, different cell types and BRCAX LCLs treated with DHA. qRT-PCR measurements were performed by the CHU de Québec Research Center
(CHUL) Gene Expression Platform, Quebec, Canada and were compliant with MIQE guidelines [33, 34].

\section{Assessment of tumor inflammatory infiltrate}

Inflammatory cell reaction was assessed in haematoxylin and eosin (H\&E) stained breast tumor sections from 15 $\mathrm{BC}$ patients, randomly selected according to their AIF1v1 expression $(\mathrm{n}=74)$ in breast adipose tissue (3 slides per patient, 45 slides total). Three methods were used to estimate the overall inflammation in each breast tumor section. First, the proportion of tumor cells and stroma within the delimited tumor area (Additional file 2: Figure S1A, B) were estimated semi-quantitatively. Tumor cell percentage (TCP) and tumor stroma percentage (TSP) were calculated as the percentage of the visible field comprised of tumor cells or stroma respectively, excluding other areas as described previously $[7,35]$.

Second, we scored peritumoral inflammatory cell infiltrate according to the Klintrup criteria (KM) [6]. Briefly, breast tumors were scored on a four-point scale based on their morphological appearance at the invasive margin (Additional file 2: Figure S1B). A KM score (KMS) of 0 was given when no increase of inflammatory cells was observed. A score of 1 denoted a mild and patchy increase of inflammatory cells, a score of 2 indicated a band-like infiltrate, and a score of 3 revealed a very prominent inflammatory reaction with frequent destruction of cancer cell islands. Inflammatory responses were subsequently classified as low grade $(0 / 1)$ or high grade $(2 / 3)$ for analysis. Lastly, to identify individual inflammatory cells and estimate their proportion within delimited tumor area, each section was divided into five distinct areas along the invasive margin as described previously [7]. Individual cells were counted at $20 \times$ magnification in 10 random boxes within each of the areas $\left(0.018 \mathrm{~mm}^{2}\right)$ resulting in a total of 50 boxes analyzed per slide. Boxes were randomly dispersed between the peritumoral and intratumoral regions. Cells outside of the tumor border, in necrotic areas and around normal lobules were excluded. Lymphocytes, plasma cells, eosinophils, macrophages and other cells (neutrophils and basophils) had characteristic morphological features that allowed them to be recognized and counted in H\&E full-faced sections (representative box depicted in Additional file 2: Figure S1C). Additional parameters included tissue location, size of the delimited tumor area, tumor nest cells or stromal cells. Assessments of the tumor inflammatory infiltrate were performed by a single investigator (FAS) blinded to clinical and pathological data with independent coscoring by a pathologist (KEI) to assess reproducibility. The inter-observer correlations were high: total cells $(r>0.99)$, lymphocytes $(r>0.99)$, plasma cells $(r=0.46)$, TCP $(r=0.78)$, TSP $(r=0.71)$ and KMS $(r=0.69)$. 


\section{Statistical analyses}

\section{Association with clinical factors}

Relationships between the expression of AIF1 transcripts (in breast tumors and adipose tissue) with clinical and metabolic parameters including age (years), weight $(\mathrm{kg})$, menopausal status, body mass index (BMI) $\left(\mathrm{kg} / \mathrm{m}^{2}\right)$, waist-hip ratio (WHR), adipose breast area $\left(\mathrm{cm}^{2}\right)$ [36], inflammatory and hormonal gene expression measured in breast adipose tissue, were assessed using Spearman correlation. A p-value $<0.05$ was considered statistically significant. Spearman correlations were adjusted for age without and with adiposity (BMI, weight or adipose breast area). All statistical analyses were performed with SAS software version 9.4 (SAS Institute Inc, Cary, NC, USA).

\section{Bioinformatics analysis}

AIF1v1 and AIF1v3 three-dimensional structures were constructed using the PDBsum program (EMBL-EBI) and vizualised with NGL Viewer application [37]. For multiple sequence alignment, the ClustalW2 server (EMBL-EBI) was used [38]. Predictive functions of each transcript were obtained with I-TASSER prediction server (ZhangLab) derived by threading the 3D models through protein function database BioLiP [39].

\section{Other procedures}

Protocols for MCF7 transfection and E1/E2 treatment, steroid extraction and 1D thin layer chromatography measurements, and crystal violet assay for determining viability of cultured cells are described in Additional file 3: Additional methods.

\section{Results}

Identification of AIF1 transcripts in BRCAX families with high risk of $B C$

Among a list of significant transcripts generated by RNA-sequencing and statistical analyses [28], specific transcripts were selected and validated by qRT-PCR to confirm their differential expression in $\mathrm{BC}$ affected and non-affected individuals in a BRCAX subgroup. The BRCAX cohort consists of 16 pairs of BC affected and unaffected sisters (one affected and one unaffected individual per family), the non-affected selected individual being the oldest sister of the family. Two splice variants of the AIF1 gene (AIF1v1 and AIF1v3) were identified as differentially expressed between the affected and unaffected sisters (Fig. 1). Indeed, AIF1 expression in BRCAX immortalized LCLs was higher in the affected sisters compared to their unaffected sisters (AIF1v1 overexpression in $11 / 16$ pairs and AIF1v3 overexpression in $8 / 16$ pairs). These results were validated by qRT-PCR (Additional file 4: Figure S2A, B) and suggested that the two transcripts might be associated with $\mathrm{BC}$; therefore, further investigation was warranted.

\section{Predictive structures, functions and interactions of AIF1 transcripts}

Since little was known about AIF1, particularly AIF1v1, and its role $\mathrm{BC}$ development, the structure of the two variants was determined to examine potential functional differences.

As shown in Fig. 2a, structurally, AIF1v3 is the longest splice variant (147aa). AIF1v3 is the most extensively characterized of the two isoforms and is considered the "wild-type". AIF1v1 is shorter (93aa) and shares with AIF1v3 a leucine zipper motif suggesting possible dimerization of the corresponding proteins. Both isoforms contain an EF-hand calcium-binding domain, the sequence

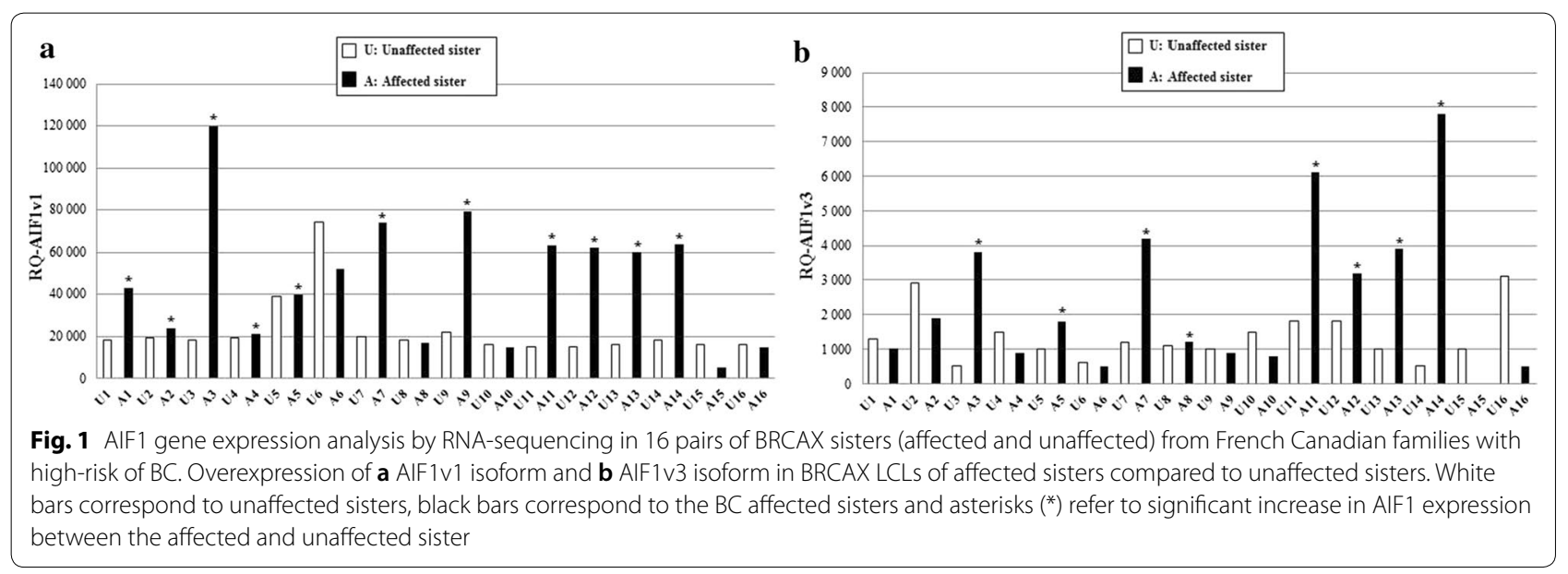




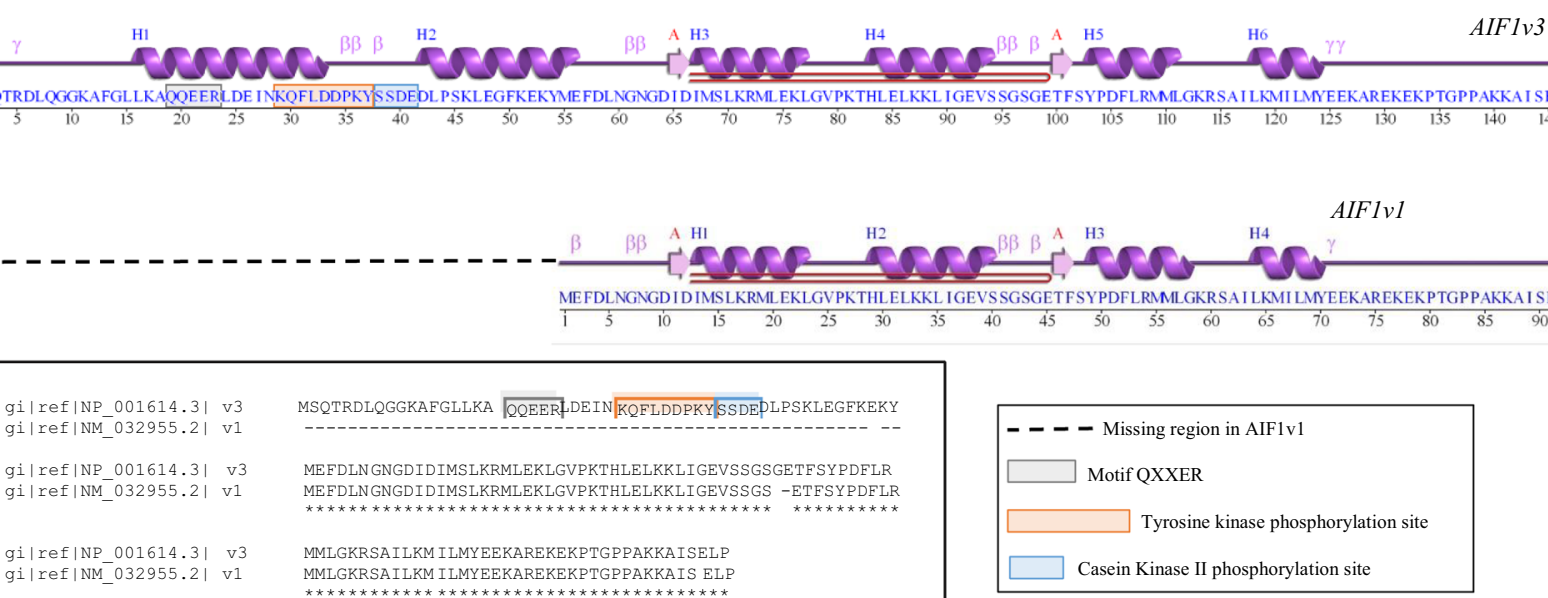

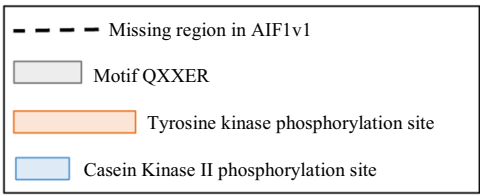

b

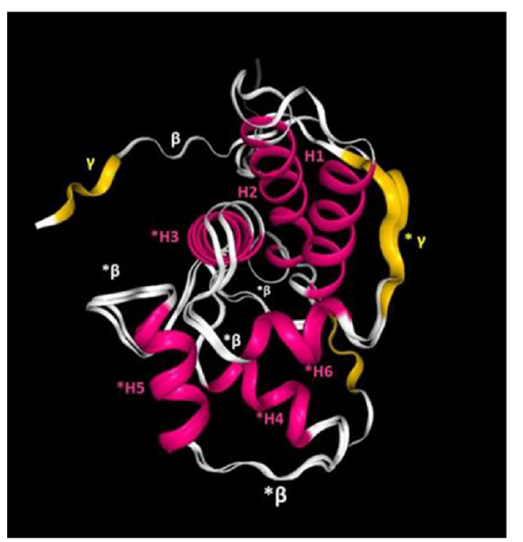

\begin{tabular}{|l|}
\hline H : Helix \\
H1 : Leu19-Leu354 \\
H2 : Asp45-Tyr57 \\
H3 : Ile70-Leu80 \\
H4 : His86-Val96 \\
H5 : Tyr106-Gly115 \\
H6 : Leu121-Tyr127 \\
\hline $\begin{array}{l}\text { B : Beta turn } \\
\gamma: \text { Gamma } \\
\text { turn }\end{array}$ \\
\hline \multicolumn{1}{c|}{ *common in both } \\
isoforms
\end{tabular}

c

\begin{tabular}{|c|c|c|c|c|c|c|}
\hline Function & \multicolumn{3}{|c|}{ AIF1v3 } & \multicolumn{3}{|c|}{ AIF1v1 } \\
\hline $\begin{array}{l}\text { Molecular } \\
\text { Function }\end{array}$ & $\begin{array}{l}\text { Calcium ion } \\
\text { binding }\end{array}$ & $\begin{array}{l}\text { Actin filament } \\
\text { binding }\end{array}$ & $\begin{array}{l}\text { Thioesterase } \\
\text { binding }\end{array}$ & $\begin{array}{l}\text { Calcium ion } \\
\text { binding }\end{array}$ & $\begin{array}{l}\text { Thioesterase } \\
\text { binding }\end{array}$ & $\begin{array}{l}\text { Calcium } \\
\text { channel } \\
\text { regulator } \\
\text { activity }\end{array}$ \\
\hline GO-Score & 0.98 & 0.88 & 0.38 & 0.89 & 0.53 & 0.53 \\
\hline Biological Process & $\begin{array}{l}\text { Positive regulation } \\
\text { of muscle } \\
\text { hyperplasia }\end{array}$ & $\begin{array}{l}\text { Response to } \\
\text { cytokine } \\
\text { stimulus }\end{array}$ & $\begin{array}{l}\text { Inflammatory } \\
\text { response }\end{array}$ & $\begin{array}{l}\text { Glucose metabolic } \\
\text { process }\end{array}$ & $\begin{array}{l}\text { Platelet } \\
\text { activation }\end{array}$ & $\begin{array}{l}\text { Platelet } \\
\text { degranulation }\end{array}$ \\
\hline GO-Score & 0.66 & 0.66 & 0.66 & 0.53 & 0.53 & 0.53 \\
\hline
\end{tabular}

Fig. 2 Predictive structure of AIF1 isoforms. a Representation of AIF1v3 and AlF1v1 secondary structures. Comparison of amino-acid sequences reveals a missing conserved region in isoform AIF1V1. Both isoforms share a leucine zipper motif that suggests possible dimerization of the corresponding proteins. Helices labelled $\mathrm{H1}, \mathrm{H} 2, \mathrm{H} 3, \mathrm{H} 4, \mathrm{H} 5$ and $\mathrm{H} 6$ and strands by their sheets, labelled A. Motifs labelled $\beta$ : beta turn, $\gamma$ : gamma turn and beta hairpin (in red, A to A). b 3D model of AIF1V1 and AIF1v3 superpimposed. c Predictive protein functions. GO gene ontology. Consensus prediction derived based on the occurrence of the $\mathrm{GO}$ terms among the selected templates 
pattern -KR-KK-GKR-, a motif typical of peptide hormone precursors, and are characterized by a wide range of biologically active sites. AIF1v3 contains a specific conserved region comprising the QXXER motif (19-23) that is important for $\mathrm{G}$ protein modulation and interactions involving synaptic transmission, a tyrosine kinase phosphorylation site (29-37) and a casein kinase II phosphorylation site (38-41) (a serine-threonine protein kinase with a wide range of substrates, many of which are involved in cell cycle regulation). This region is missing in AIF1v1 suggesting a specific functional role. 3D macromolecular models of both isoforms aligned with common sites highlighted are depicted in Fig. 2b.

Figure 2c reports predictions regarding molecular functions and biological processes of the two isoforms based on the occurrence of GO terms. While their molecular functions appear to be highly similar, the biological processes in which they are involved seem different. Indeed, AIF1v3 is more likely to be associated with the regulation of muscle hyperplasia and inflammatory responses, which is consistent with previous studies that identified this isoform as a crucial inflammatory mediator [14].

AIF1v1, on the other hand, seems to be involved in glucose metabolism and platelet activation suggesting a role in platelet glycolysis, but there is no data in the literature regarding this particular isoform. Glucose metabolism plays a critical role in the production, activation, and survival of platelets according to a recent study [40] and relationships between tumor and the hemostatic system is being recognized as an important BC regulator [41]. Considering these results, the potential roles and characterization of AIF1 were further explored.

\section{Characterization of AIF1 transcripts in breast tumors and human cancer cell lines}

Using cohort 1, presented in Table 1, gene expression analyses by qRT-PCR showed that both AIF1v1 and $A I F 1 v 3$ isoforms are expressed in breast tumors of varying severity (Fig. 3a, b) and AIF1v1 mRNA levels were higher than AIF1v3, considered the wild-type. Both isoforms seemed significantly more expressed in the less severe BC, i.e. ductal carcinoma in situ (DCIS) and luminal $\mathrm{A} / \mathrm{B}(\mathrm{ER}+$ and/or $\mathrm{PR}+)$, and decreased with increasing $\mathrm{BC}$ severity, i.e. Her2+ (ER-/PR-/HER2+) and triple negative tumors (ER-/PR-/HER2-). This result suggests that AIF1 might be associated with BC initiation and progression. A similar experiment was conducted with 16 other breast tissues divided into benign structures, atypical ductal hyperplasia (ADH), DCIS and invasive ductal carcinoma (IDC). Results revealed little $A I F 1 v 1$ and $A I F 1 v 3$ expression in benign and ADH but were augmented in DCIS and IDC with expression rates significantly higher in DCIS (Additional file 5: Figure S3A, B). A decrease in cell viability was also observed in transfected MCF7 cells with AIF1v1 as compared to controls (Additional file 6: Figure S4A, B). These findings corroborate our previous result showing increased expression of AIF1 isoforms in breast tumors with the highest levels found in the less severe tumors (DCIS and luminal). However, AIF1v3 seems to be more expressed in triple negative breast tumors (Fig. 3b) and IDC than AIF1v1. This finding suggests that these two isoforms behave differently and may perform different roles in $\mathrm{BC}$ development. No expression was observed in human $B C$ cell lines MCF7, ZR75, SKBR3, MDA-MB-231, and BT20 (Fig. 3a, b), epithelial cancer cell lines OV90, OVCAR3, LNCaP and HEK-293, and breast epithelial non-cancerous cell line MCF10A (Additional file 7: Figure S5A, B). This discovery implies that AIF1 is most probably not expressed in the epithelium and might rather be expressed via the tumor microenvironment (TME).

\section{Characterization of AIF1 transcripts in tumor microenvironment}

To elucidate whether AIF1 expression in breast tumors is due to the tumor microenvironment (TME), RNA was extracted from 74 samples of breast adipose tissue from BC patients and analyzed by qRT-PCR. Results showed that AIF1v1 is highly expressed in breast adipose tissue, as well as AIF1v3 (measured in 6 random samples), suggesting that AIF1 could be an important factor of the TME (Fig. 3c). Considering that major components of the breast adipose tissue include fibroblasts, adipocytes and immune cells, we further characterized cell types expressing the two isoforms. Figure 3d shows that AIF1 is mostly expressed in monocytes and macrophages, particularly $A I F 1 v 3$, but not in breast fibroblasts and adipocytes (mammary and abdominal). As two major polarization states have been described for macrophages, the classically activated type 1 (M1) and the alternatively activated type 2 (M2), we further investigated which type of macrophages express AIF1. The human monocytic cell line (THP-1) was differentiated into macrophages $\mathrm{M} 1$ and M2, and the expression of both isoforms was analyzed by qRT-PCR. AIF1v3 was more strongly expressed in differentiated than undifferentiated macrophages, and this expression seemed higher in M1 than M2 macrophages (Fig. 3e). AIF1v1 expression, however, was practically similar in differentiated and undifferentiated macrophages but slightly higher in M1. Results suggest that AIF1v1 is probably mostly expressed in other cells of the breast TME. 

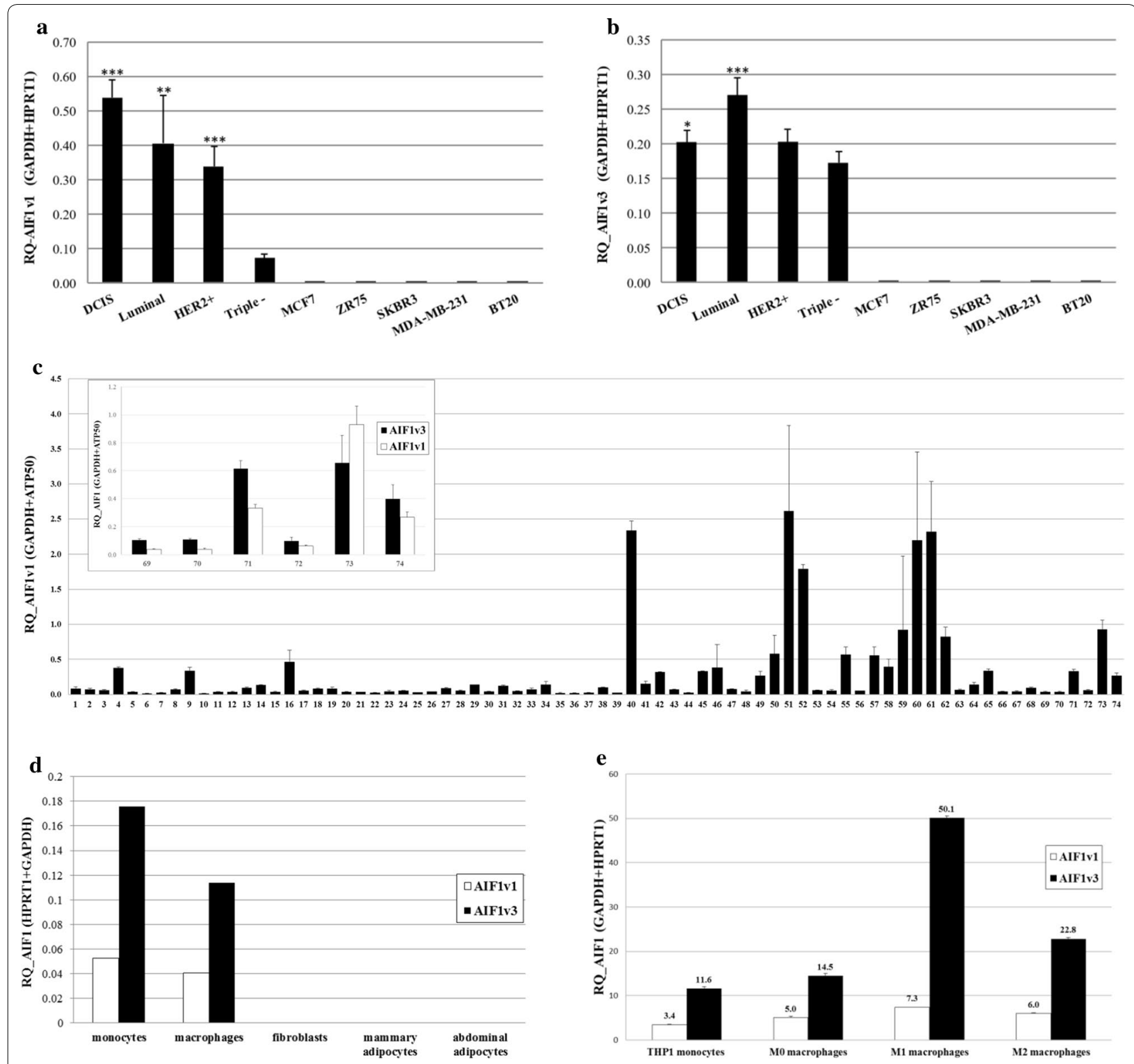

Fig. 3 Characterization of AIF1 isoforms in breast tumors and tumor microenvironment. Expression of a AIF1V1 and $\mathbf{b}$ AIF1V3 in breast tumors of varying severity (DCIS, luminal A/B (ER+ and/or PR+), HER2+ (ER-/PR-/HER2+), triple negative (ER-/PR-/HER2-) and human BC cell lines (MCF7, ZR75, SKBR3, MDA-MB-231, BT20). c AlF1v1 in breast adipose tissue (top panel: comparison of AlF1V1 and AlF1v3 expression in six samples of breast adipose tissue). d AIF1 isoforms in various cell types of the breast tumor microenvironment (monocytes, macrophages, fibroblasts and adipocytes). e AIF1 isoforms in THP-1 monocytes and differentiated macrophages (M1, M2). Data shown as mean \pm SD; Each subtype is compared to triple negative with ${ }^{* * *} p<0.01,{ }^{* *} p<0.05,{ }^{*} 0.05<p<0.1$

\section{Assessment of tumor inflammatory infiltrate}

As displayed in Table 2, the relationship between tumor inflammatory infiltrate in breast tumors and AIF1v1 expression in corresponding breast adipose tissue was examined. Quantification of inflammatory cell reactions was assessed on full-section haematoxylin and eosin slides for $15 \mathrm{BC}$ patients (3 slides per patient, 45 slides in total). Patients were clustered into three groups (tertiles) according to their AIF1v1 expression levels (low, med, high). Tumor cell percentage (TCP) and tumor stroma percentage (TSP) were similar in each group and no significant differences were observed. Using the Klintrup-Mäkinen (KM) criteria, the peritumoral inflammatory cell response was graded as "low KM score" in $8 \mathrm{BC}$ patients (53.33\%) and "high KM score" in $7 \mathrm{BC}$ patients (46.67\%). In general, all patients in the high AIF1v1 
Table 2 Distribution of the infiltrating immune cells, KM scores, TSP, TCP and NP between the different AIF1v1 expression groups in breast tumors

\begin{tabular}{|c|c|c|c|c|}
\hline \multirow[t]{2}{*}{ Variables } & \multicolumn{3}{|c|}{ AIF1v1 expression } & \multirow[t]{2}{*}{$p$-value } \\
\hline & Low $(n=5)$ & Med $(n=5)$ & High $(n=5)$ & \\
\hline $\begin{array}{l}\text { Total cells } \\
\text { count }^{\mathrm{a}}\end{array}$ & $255.7 \pm 95.5$ & $327.7 \pm 215.4$ & $1108.6 \pm 847.5$ & $0.03^{*}$ \\
\hline $\begin{array}{l}\text { Lymphocytes } \\
\text { count }^{\text {a }}\end{array}$ & $251.1 \pm 98.5$ & $321.9 \pm 218.4$ & $1095.2 \pm 838.6$ & $0.03^{*}$ \\
\hline $\begin{array}{l}\text { Plasmocytes } \\
\text { count }^{\mathrm{a}}\end{array}$ & $2.8 \pm 1.5$ & $4.0 \pm 3.8$ & $8.3 \pm 2.7$ & $0.02^{*}$ \\
\hline $\mathrm{TCP}$ & $67.8 \pm 11.8$ & $60.0 \pm 8.0$ & $64.1 \pm 8.4$ & $0.46^{*}$ \\
\hline $\mathrm{TSP}^{\mathrm{b}}$ & $32.2 \pm 11.8$ & $40.0 \pm 8.0$ & $35.9 \pm 8.4$ & $0.46^{*}$ \\
\hline KMS high & $1(20 \%)$ & $1(20 \%)$ & $5(100 \%)$ & $0.02^{* *}$ \\
\hline
\end{tabular}

TCP tumor cell percentage, TSP tumor stroma percentage, KMS Klintrup and Mäkinen score

* Analysis of variance using one-way ANOVA. ** Fisher's Exact test. Italic text indicates a statistically significant difference with a p-value $<0.05$

Data presented as mean ${ }^{a}$ number of cells, ${ }^{b}$ percentage per group of patients $\pm S D$ and ${ }^{c}$ number of individuals (\%)

expression group had a high KM score while $80 \%$ of patients in med and low groups had a low KM score.

Patients who overexpressed AIF1v1 also had a higher number of total inflammatory cells while med and low groups had significantly lower cell numbers (Fig. 4a). Lymphocytes and plasma cells were primarily identified with relatively few eosinophils, macrophages or other cell types (these cell types were excluded from further analysis). Lymphocytes were the most abundant cells in all groups and were equally distributed between peritumoral and intratumoral regions (Fig. 4b). Furthermore, significant correlations were found between breast adipose AIF1v1 expression with total number of lymphocytes ( $\mathrm{rs}=0.63 ; \mathrm{p}=0.01)$, number of intratumoral lymphocytes $(\mathrm{rs}=0.80, \mathrm{p}=0.0006)$, number of peritumoral lymphocytes $(\mathrm{rs}=0.58, \mathrm{p}=0.03)$ and total number of plasma cells ( $\mathrm{rs}=0.67, \mathrm{p}=0.005)$, respectively.

Overall, BC patients with high AIF1v1 breast adipose expression had more cell infiltrate at the invasive margin (KM score) and a significantly higher number of infiltrating immune cells consisting predominantly of lymphocytes, both in the peri and intra-tumoral regions.

\section{Functional role of AIF1}

To further investigate potential functions of AIF1 and taking into consideration its high expression in breast adipose tissue, we measured the conversion rate of ${ }^{14} \mathrm{C}$-estradiol (E2) to estrone (E1) (and inversely) in transfected MCF7 cell lines. The results revealed that the estrone/17beta-estradiol conversion rate, regardless of E2/E1 concentration and incubation time, was similar in MCF7 cells (control) and transfected MCF7 cells with pcDNAv1 and pcDNAv3 (Additional file 8: Figure S6) demonstrating that AIF1v1 and AIF1v3 do not intervene in the E2/E1 conversion rate.

Given its implication in inflammation, the potential biological process in which AIF1 could intervene in the metabolic pathway of polyunsaturated fatty acids (PUFAs) was investigated. Long-chain omega-3 FA eicosapentaenoic acid (EPA) and DHA are important in generating bioactive lipid mediators that are necessary for inflammation resolution [42]. Analyses of BRCAX immortalized LCLs supplemented with various concentrations of EPA, or a mixture of EPA: DHA for $24 \mathrm{~h}$ showed a significant decrease in AIF1v1 and AIF1v3 expression when cells were incubated with $40 \mu \mathrm{M}$ of DHA $(\mathrm{p}<0.05)$ for both the affected and unaffected BRCAX sisters (Additional file 9: Figure S7A, B). An independent assay performed with incubation of BRCAX LCLs of the same sister pair with a higher DHA concentration and over a longer period revealed that $A I F 1 v 1$ and AIF1v3 expression levels were consistently lower after DHA supplementation (Fig. 5). The decrease persisted over time and was dose-dependent.

\section{AIF1 expression and clinical parameters of BC patients}

Using our cohorts presented in Table 1, AIF1 expression in breast tumors $(\mathrm{n}=13)$ and breast adipose tissue $(n=74)$ was then investigated in relation to clinical parameters of BC patients (Table 3 ).

AIF1v1 expression in breast tumors significantly and positively correlated with age $(\mathrm{p}=0.02)$, menopausal status $(\mathrm{p}=0.05)$ and breast adipose expression of Cytochrome P450 Family 19 Subfamily A Member 1 (CYP19A1) $(\mathrm{p}=0.03)$ and IL-6 $(\mathrm{p}=0.006)$ whereas AIF1v3 was only positively correlated with breast adipose expression of cyclooxygenase-2 (COX2) $(\mathrm{p}=0.04)$. Expression of each isoform in breast tumors also correlated with each other $(\mathrm{r}=0.63 ; \mathrm{p}=0.02)$.

In breast adipose tissue, AIF1v1 expression significantly and positively correlated with weight $(\mathrm{p}=0.03)$, waist-hip ratio (WHR) $(\mathrm{p}=0.05)$, adipose breast area $(p=0.008)$ and breast adipose expression of CYP19A1 $(\mathrm{p}<0.0001)$, estrogen receptor alpha $(E R \alpha)(p<0.0001)$, leptin $(\mathrm{p}<0.0001), \operatorname{COX} 2(\mathrm{p}<0.0005)$, IL-6 $(\mathrm{p}<0.0001)$ and TNF $\alpha(\mathrm{p}=0.0002)$. When adjusted for age, these correlations were still highly significant for all variables except weight $(\mathrm{p}=0.06)$ and WHR $(\mathrm{p}=0.14)$. These correlations were also highly significant when adjusting for age and adiposity (body mass index (BMI), weight or adipose breast area).

Similarly to Fig. 3a, AIF1v1 was highly expressed in the less severe tumors and decreased with increasing disease 


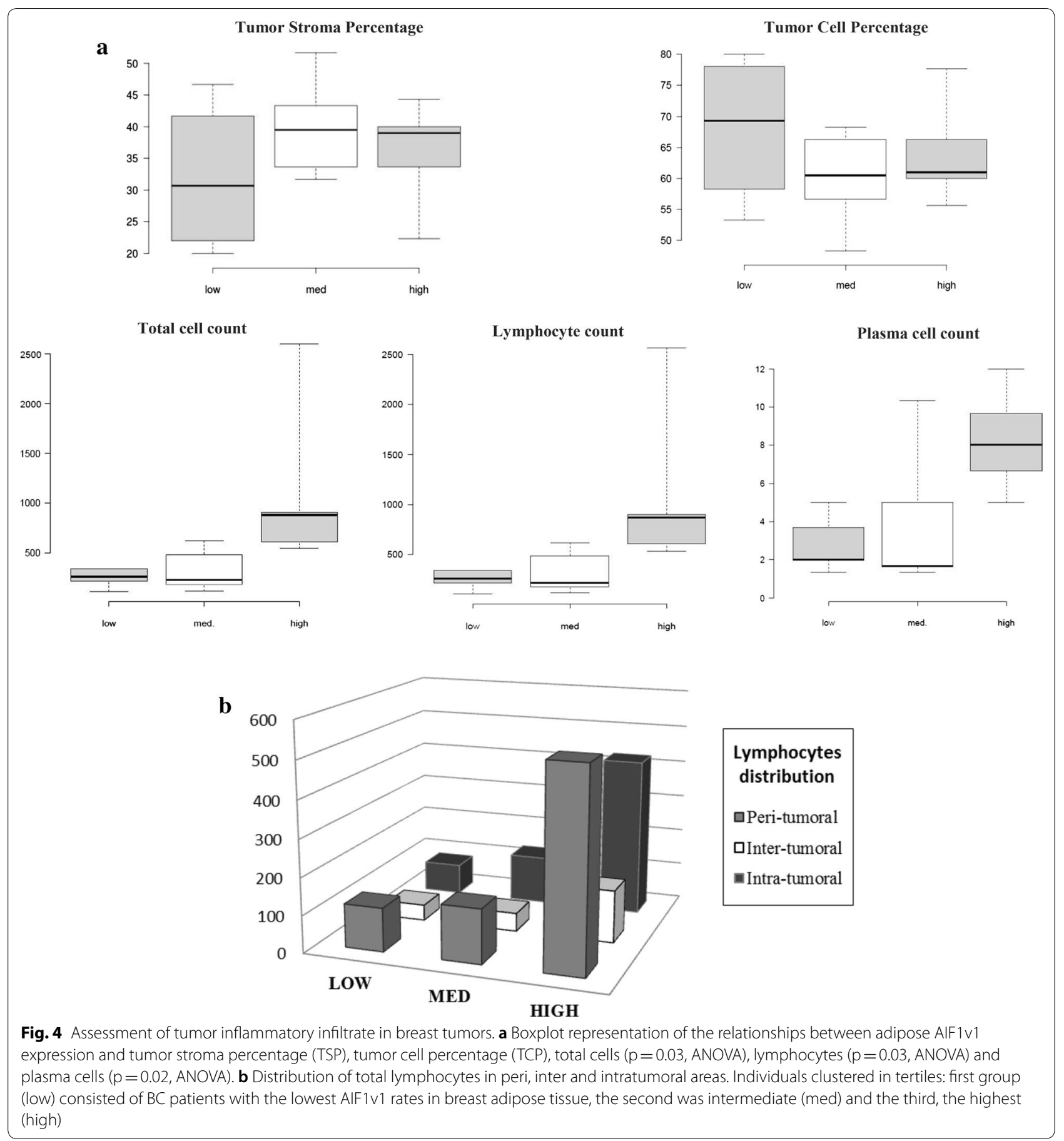

severity when measured in the breast adipose tissue (Additional file 10: Figure S8).

These results highlight the importance of AIF1v1 isoform in $\mathrm{BC}$ and provide evidence of its interaction with a series of proinflammatory cytokines such as IL-6 and TNF $\alpha$, adipokines such as leptin and other important variables that play key roles in $\mathrm{BC}$ progression.

\section{Discussion}

AIF1 is a cytoplasmic, EF-hand calcium-binding, inflammation-responsive scaffold protein that is implicated in various disease processes. Originally identified in chronically rejecting cardiac allografts, it was initially demonstrated that AIF1 was a modulator of the immune response [43]. Previous reports have described a range 


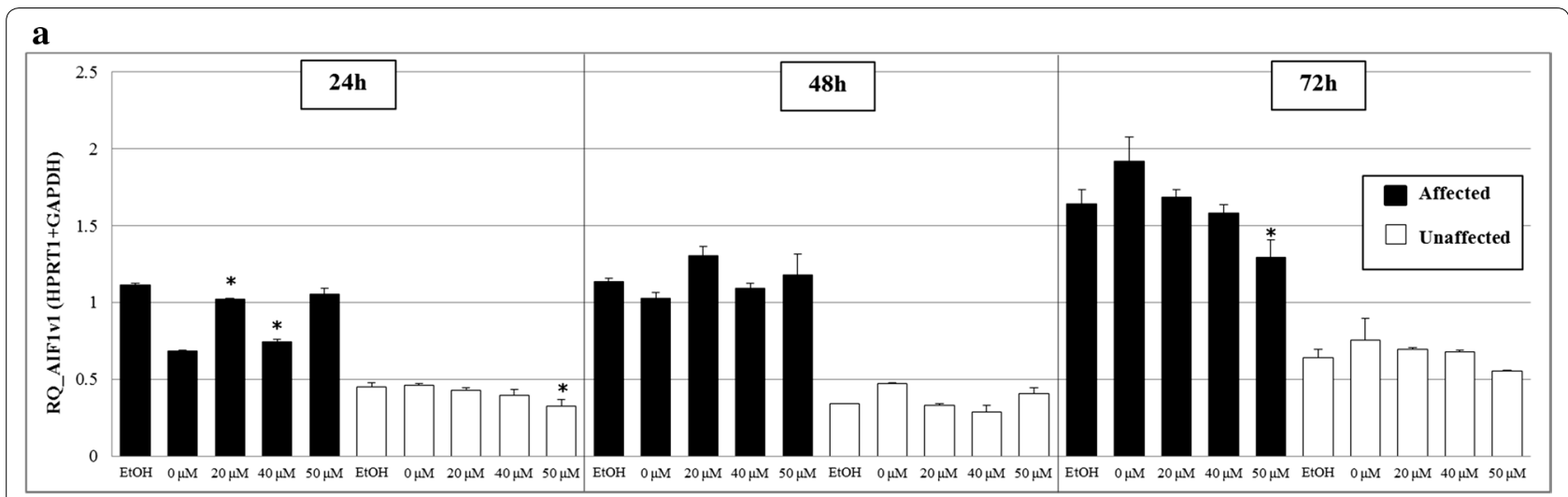

b

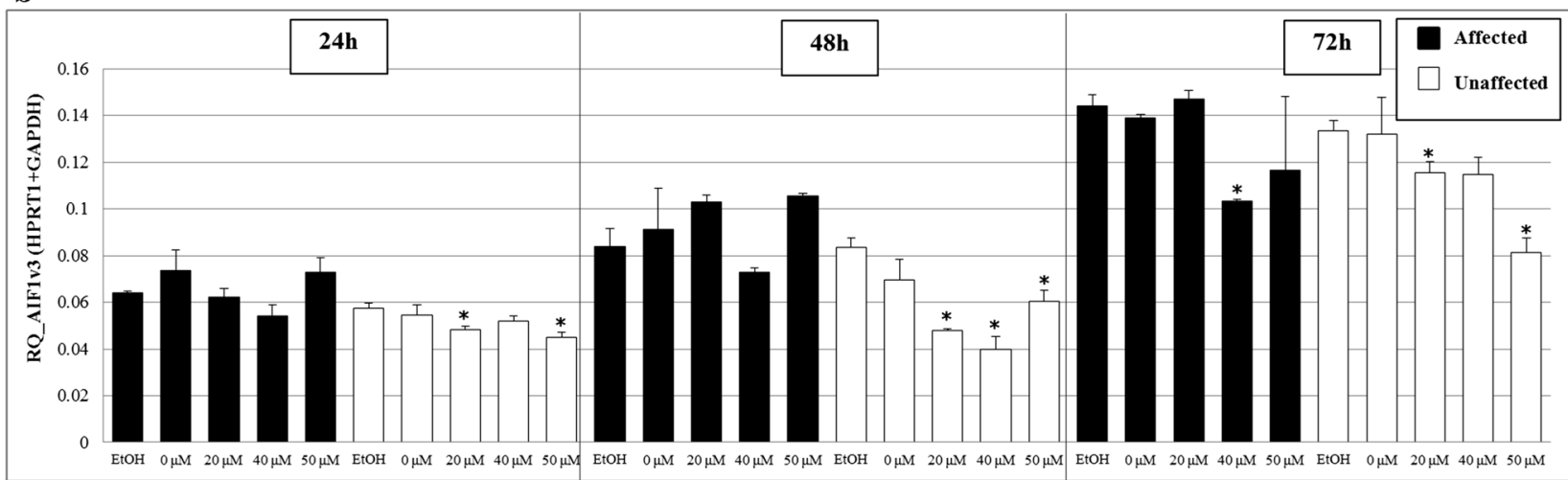

Fig. 5 Effect of long-chain omega-3 fatty acid docosahexaenoic acid (DHA) on the expression of a AIF1v1 and $\mathbf{b}$ AIF1 V3. BRCAX LCLs of affected and unaffected sisters were treated with 0,20,40 and $50 \mu \mathrm{M}$ of DHA for 24, 48 and $72 \mathrm{~h}$. Data shown as mean \pm SD. Significant values are highlighted with asterisks (*), each sample was compared to control (ethanol)

of AIF1-related splice variants, and three splice isoforms have been identified: AIF1v1, AIF1v2 and AIF1v3 (GenBank accession nos. NM_032955, NM_004847 and NM_001623, respectively) but to date, there are no studies published on AIF1v1. In the present study, we investigated, for the first time, the functional and structural differences of AIF1v1 and AIF1v3, and their expression in breast tumors and breast tumor microenvironment. We identified AIF1 isoforms in a cohort of BRCAX individuals issued from families with high $\mathrm{BC}$ risk. In these families, AIF1v1 and AIF1v3 were significantly and differentially expressed between $\mathrm{BC}$ affected and unaffected sisters within the same families, which led us to investigate their implication in $\mathrm{BC}$ development.

Cells transfected with AIF1v1 showed reduced cell viability, in agreement with a previous study with AIF1 in pancreatic cells [17]. In addition, both AIF1 isoforms, but mainly $A I F 1 v 1$, were highly expressed in the less severe BC tumors (DCIS and luminal subtype) suggesting their involvement in tumor initiation and progression. Two previous studies demonstrated that AIF1v3 in transfected human $\mathrm{BC}$ cell lines could promote $\mathrm{BC}$ cell proliferation via the NF- $\mathrm{B}$ pathway and enhance cell migration by activation of $\mathrm{p} 38$-MAPK pathway suggesting a possible role in $\mathrm{BC}$ progression $[25,26]$. However, roles of both isoforms and interactions with other proteins in the tumor microenvironment have not been elucidated.

Our data revealed that while AIF1 isoforms are not present in epithelial cells, they are highly expressed in breast adipose tissue. Furthermore, we observed large differences in expression rates and isoform sources. While activated macrophages are the major source of AIF1v3 in breast adipose tissue, which is consistent with previous findings in human white adipose tissue [15], AIF1v1 appears to be significantly less expressed by macrophages, suggesting that its high expression is due to another immune cell type. Since BRCAX LCLs displayed high AIF1v1 mRNA expression levels, we hypothesized that lymphocytes might be a major source. The latter result is supported by a previous study where several T-cell lines were screened by real-time PCR to compare AIF1 isoform expression levels with those of peripheral blood mononuclear cells and showed a higher expression 
Table 3 Spearman's correlation between AIF1v1/v3 expression in breast tumors and breast adipose tissue and variables

\begin{tabular}{|c|c|c|c|c|c|c|}
\hline \multirow[t]{3}{*}{ Variable } & \multirow[t]{3}{*}{$N$} & \multicolumn{2}{|l|}{ Breast tumors } & \multirow[t]{3}{*}{$\mathbf{N}$} & \multicolumn{2}{|c|}{ Breast adipose tissue } \\
\hline & & AIF1v1 expression & AIF1v3 expression & & AIF1v1 expression & $\begin{array}{l}\text { AlF1v1 } \\
\text { expression } \\
\text { adjusted* }\end{array}$ \\
\hline & & $\operatorname{Rs}(p)$ & $\operatorname{Rs}(p)$ & & $\operatorname{Rs}(p)$ & Rs (p) \\
\hline Age (years) & 13 & $0.65(0.02)$ & $0.52(0.06)$ & 74 & $0.16(0.16)$ & - \\
\hline Weight (kg) & 13 & $0.05(0.85)$ & $0.17(0.58)$ & 74 & $0.25(0.03)$ & $0.22(0.06)$ \\
\hline BMI $\left(\mathrm{kg} / \mathrm{m}^{2}\right)$ & 13 & $0.22(0.47)$ & $0.30(0.32)$ & 74 & $0.19(0.09)$ & $0.16(0.16)$ \\
\hline Waist-hip ratio & 13 & $0.33(0.27)$ & $0.37(0.21)$ & 74 & $0.23(0.05)$ & $0.17(0.14)$ \\
\hline Menopausal status & 13 & $0.55(0.05)$ & $0.08(0.78)$ & 74 & $0.19(0.09)$ & $0.06(0.57)$ \\
\hline Adipose breast area $\left(\mathrm{cm}^{2}\right)$ & 13 & $0.32(0.28)$ & $0.27(0.36)$ & 74 & $0.31(0.008)$ & $0.27(0.02)$ \\
\hline CYP19A1 expression & 12 & $0.63(0.03)$ & $0.39(0.21)$ & 74 & $0.83(<0.0001)$ & $0.82(<0.0001)$ \\
\hline ERa expression & 12 & $0.37(0.24)$ & $0.08(0.79)$ & 74 & $0.49(<0.0001)$ & $0.47(<0.0001)$ \\
\hline Leptin expression & 7 & $0.39(0.38)$ & $0.21(0.64)$ & 74 & $0.63(<0.0001)$ & $0.62(<0.0001)$ \\
\hline COX2 expression & 7 & $0.61(0.15)$ & $0.79(0.04)$ & 73 & $0.40(0.0005)$ & $0.40(0.0006)$ \\
\hline IL-6 expression & 7 & $0.89(0.006)$ & $0.64(0.12)$ & 74 & $0.60(<0.0001)$ & $0.59(<0.0001)$ \\
\hline TNFa expression & 6 & $0.08(0.87)$ & $-0.26(0.62)$ & 64 & $0.45(0.0002)$ & $0.47(<0.0001)$ \\
\hline
\end{tabular}

Rs Spearman correlation coefficient, $p$ p-value, BMI body mass index, CYP19A1 Cytochrome P450 Family 19 Subfamily A Member 1, Era estrogen receptor alpha, COX2 cyclooxygenase 2, IL-6 interleukin 6, TNFa tumor necrosis factor alpha

Bold italics text indicates a statistically significant difference with a $\mathrm{p}$-value $<0.05$, text in italics shows a $\mathrm{p}$-value between 0.05 and 0.1 . Adipose breast area is estimated from mammograms [36]

* Adjusted for age when applicable

of the AIF1v1 isoform in all immortalized cell lines screened [44].

Furthermore, bioinformatics analyses showed a significant structural difference between both isoforms. AIF1v1 appears to lack an entire region including specific conserved motifs and binding sites that are present in AIF1v3. This observation is of substantial relevance and could explain why the two isoforms may be differentially expressed by various cell types regulated by cytokines and growth factors of the environment and thus, behave differently. Previous studies demonstrated that AIF1v3 is strongly expressed in macrophages and activated T-cells [19, 44, 45], but no data exists on AIF1v1. TILs and TAMs have essential roles in mediating tumor progression in all BC subtypes. TAMs have been shown to possess features of the pro-inflammatory M1 phenotype in the early stages of tumorigenesis, but switch to an antiinflammatory M2-like phenotype, with the acquisition of proangiogenic capability [46]. Furthermore, IL-6 and other cytokines secreted by M1-polarized macrophages have been shown to be involved in a wide range of tumorigenic processes [47].

This is concordant with our results showing that AIF1v3 is more highly expressed in M1 than M2 macrophages, its expression being the highest in DCIS and luminal, and decreasing as $\mathrm{BC}$ prognostic severity increases. A recent study showed that RAW264.7 cells overexpressing AIF1v3 increased markers associated with M2 polarization and decreased those associated with M1 polarization [48]. However, these results were carried out in a specific transfected subset of colonystimulating factor (CSF1)-induced macrophages in the context of hepatocellular carcinoma and not BC. In addition, M2 polarization is a complex process that involves multiple factors other than CSF1, such as monocyte chemoattractant protein-1 [49]. Nevertheless, in our case, AIF1v3 was expressed in both M1 and M2 macrophages with significantly higher expression in the M1 phenotype.

In one retrospective study of 53 mastectomy samples, increased B-cell and T-cell immune infiltrate was identified in benign ductal hyperplasia and was increased in DCIS and highest in invasive BC [50]. This suggests that a particular class of lymphocytes is responsible for its expression in these particular BC subtypes. Two TILs phenotypes have been described: type 1 , which is assumed to have anti-tumor properties and type 2, which may promote an anti-inflammatory immune response that could enhance tumor growth $[51,52]$. The distribution of these different types of lymphocytes in each $\mathrm{BC}$ subtype needs to be further investigated. Furthermore, whether AIF1v1 is only expressed by a particular class of lymphocytes requires further study.

Previous studies have established that cancer development and progression depend on complex interactions between the tumor and the local inflammatory response [53], and a number of immune cell types implicated 
in this response have been described $[4,5,7,54]$. Our assessment of the tumor inflammatory cells infiltrate in breast tumors showed that adipose AIF1v1 was associated with the number of lymphocytes infiltrating breast tumors in both the peri and intra-tumoral regions and total number of plasma cells, which allow us to confirm our previous hypothesis. It has been reported that the prognostic significance of tumor-infiltrating $\mathrm{T}$ cells in breast carcinoma depends on their relative density and tissue location (peri or intra-tumoral) [55]. Given the functional heterogeneity of TILs, the link between the tissue location of TILs infiltrate and AIF1v1 expression would need to be further investigated.

It is well known that estrogens, which are expressed in many immune cells, modulate inflammatory cytokine gene expression [56-59]. A previous study reported that E2 increased AIF1v3 expression in a RAW264.7 murine macrophage cell line [60]. However, our analysis showed that AIF1v3, as well as AIF1v1, do not interfere with the biological activity of estrogens in MCF7 cells thus the effect of estrogens on AIF1 is likely due, in part, to another mechanism.

As for omega-3 FA, it has been reported that they decrease cell proliferation and induce apoptotic cell death in human $B C$ cells through the NF- $\mathrm{KB}$ cell pathway [61], and it is established that AIF1 promotes BC proliferation via activation of the NF- $\mathrm{kB} /$ cyclin D1 pathway [25]. This may explain our results showing the ability of DHA to modulate AIF1v1 and AIF1v3 expression in BRCAX LCLs in a dose-dependent manner. This is of interest because it shows for the first time that omega-3 FA, namely DHA, may potentially work as adjuvants and safe complementary therapies to standard cancer treatment [62-64], and prevent tumor growth and progression by reducing AIF1v1 and AIF1v3 expression in BC patients, particularly those exhibiting less aggressive tumors.

Concerning clinical and metabolic phenotypes in $\mathrm{BC}$ patients, AIF1v1 was significantly correlated with age and menopausal status in breast tumors. Since this is the first time these relations have been observed, the influence of menopause on AIF1v1 deserves further investigation. AIF1 was also positively correlated with weight, WHR and adipose breast area in mammograms. These significant correlations with adipose AIF1 expression are in agreement with previous findings suggesting AIF1 is an adipokine associated with clinical parameters related to obesity [15]. The fact that AIF1v1 expression was strongly associated with CYP19A1, leptin and ER $\alpha$ shows that it is involved in this pathway and plays a significant role in adipose-inflammation induced BC. Indeed, CYP19A1 provides instructions for making an enzyme called aromatase. Aromatase expression and activity in the breast adipose tissue is upregulated by leptin and inflammatory mediators and is associated with increased tissue levels of COX2 and prostaglandin E2 (PGE2) [65]. The upregulation and associated effects can drive aberrant estrogen production within the mammary tissue, thereby promoting $\mathrm{BC}$ tumorigenesis. Finally, its association with inflammatory factors such as COX2, IL- 6 and TNF $\alpha$ provides further evidence that AIF1v1 is a key regulator of inflammation in the breast tumor microenvironment and interacts with a wide variety of cytokines and adipokines.

Taken together, these results imply that AIF1v1 can potentially regulate the recruitment and activation of inflammatory cells, particularly lymphocytes, and redirect the immune response to promote the construction of a microenvironment that is more suitable for breast cancer cell progression. The underlying mechanism is yet to be elucidated. However, we can hypothesize it implies the production of TNF $\alpha$ by AIF1v1-activated lymphocytes, which will lead to the activation of NF- $\mathrm{kB}$, thereby promoting the production of IL-6 and other cytokines, and growth-factor signals.

\section{Conclusion}

Our results shed some light on the importance of the AIF1v1 isoform and its role in breast tumor progression. Given that AIF1 in highly expressed in the less severe breast tumors, it may prove useful as a favorable prognostic factor for $\mathrm{BC}$. We also provide pertinent information on how both AIF1 isoforms relate to the breast tumor microenvironment. Importantly, we have shown that DHA can potentially decrease AIF1 expression, which may reduce inflammation-induced $\mathrm{BC}$. The highly significant results obtained in our patient cohorts need to be further investigated to evaluate whether AIF1 may be useful as a therapeutic target for $\mathrm{BC}$.

\section{Additional files}

Additional file 1: Table S1. Primer sequence and gene description.

Additional file 2: Figure S1. Estimation of inflammation reaction methods. (A) Delimitation of tumor area and estimation of tumor cell percentage (TCP) and tumor stroma percentage (TSP); (B) Scoring of general inflammatory infiltrate at the invasive margin (Klintrup criteria); (C) Representation of inflammatory cell counting at $20 \times$ magnification in one random box in the breast tumor $\left(0.018 \mathrm{~mm}^{2}\right)$.

Additional file 3. Additional methods.

Additional file 4: Figure S2. Validation of AIF1 expression in BRCAX immortalized lymphoblastoid cells (LCLs) by qRT-PCR in (A) affected sister and (B) non-affected sister. $A=$ affected; $N A=$ non-affected.

Additional file 5: Figure S3. Expression of AlF1 in mammary tissue in isoforms (A) AIF1v1 and (B) AIF1v3. ADH = Atypical ductal hyperplasia; $\mathrm{DCIS}=$ Ductal carcinoma in situ; IDC = Invasive ductal carcinoma.

Additional file 6: Figure S4. (A) Analysis of cell viability by crystal violet staining was performed on equal numbers of MCF7 breast cancer cells 
plated in a 12-well cell culture dish. The cells were transfected with (1) MCF7 alone (2) transfection agent (jetPRIME) 3) empty vector (pCDNA3.1 $(+)$ ) and (4) pcDNA3.1 (+)-AlF1v1 and let grown for 4 days. The purple color reflects the number of colonies formed after 4 days. A decrease in the number of colonies indicates decreased proliferation or increased cell death in presence of AIF1. (B) Relative expression levels of AIF1V1 mRNA by real-time PCR. The MCF7 cells seeded in 12-well plates were transfected with (1) MCF7 alone (2) transfection agent (jetPRIME) (3) empty vector (pcDNA3.1(+)) and (4) pcDNA3.1(+)-AIF1v1. HPRT1 was used as an internal control.

Additional file 7: Figure S5. Expression of AIF1V1 (A) and AIF1V3 (B) in cancer cell lines.

Additional file 8: Figure S6. Conversion of E1/E2 at different incubation time periods. $\mathrm{E} 1=$ Estrone; $\mathrm{E} 2={ }^{14} \mathrm{C}$-estradiol.

Additional file 9: Figure S7. AlF1v1 (A) and AIF1v3 (B) expression at varying concentrations of EPA/DHA EPA = Eicosapentaenoic acid; DHA = Docosahexaenoic acid.

Additional file 10: Figure S8. Distribution of breast adipose AIF1v1 expression in $\mathrm{BC}$ patients diagnosed with various breast tumors: ductal carcinoma in situ (DCIS), luminal A/B (ER+ and/or PR+), HER2+ (ER-/ $\mathrm{PR}-/ \mathrm{HER} 2+$ ) and triple negative (ER-/PR-/HER2).

\section{Abbreviations}

ADH: atypical ductal hyperplasia; AIF1: allograft-inflammatory factor-1; ATCC : American Type Culture Collection; ATP5O: ATP synthase subunit O; BC: breast cancer; BMI: body mass index; COX2: cyclooxygenase-2; CSF1: colony-stimulating factor 1; CYP19A1: Cytochrome P450 Family 19 Subfamily A Member 1; DCIS: ductal carcinoma in situ; DHA: docosahexaenoic acid; E1: estrone; E2: ${ }^{14} \mathrm{C}$-estradiol; EPA: eicosapentaenoic acid; ER: estrogen receptor; ERa: estrogen receptor alpha; FFPE: formalin-fixed and paraffin-embedded; GAPDH: glyceraldehyde-3-phosphate dehydrogenase; G6PD: glucose-6-phosphate dehydrogenase; HER2: human epidermal growth factor receptor 2; H\&E: haematoxylin and eosin; HPRT1: hypoxanthine guanine phosphoribosyl transferase 1; IDC: invasive ductal carcinoma; IL-6: interleukin-6; KM: KlintrupMäkinen criteria; KMS: KM score; LCLs: lymphoblastoid cells; NF-KB: nuclear factor-kappa B; PGE2: prostaglandin E2; PMA: phorbol 12-myristate 13-acetate; PR: progesterone receptor; PUFAs: polyunsaturated fatty acids; TAMs: tumorassociated macrophages; TCP: tumor cell percentage; TILs: tumor-infiltrating lymphocytes; TME: tumor microenvironment; TNFa: tumor necrosis factor alpha; TSP: tumor stroma percentage; WHR: waist-hip ratio.

\section{Authors' contributions}

FD and CD designed the research protocol. FAS and GO conceived, designed and performed the experiments. SJ contributed samples. FAS and KEI performed the analysis on inflammation. FAS, FD and CD drafted the manuscript. Critical revision was done by all authors. All authors read and approved the final manuscript.

\section{Author details}

${ }^{1} \mathrm{CHU}$ de Québec Research Centre and Cancer Research Centre-Laval University, 2705 Laurier Boulevard, Quebec City, QC G1V 4G2, Canada. ${ }^{2}$ Department of Molecular Medicine, Faculty of Medicine, Laval University, Quebec City, QC, Canada. ${ }^{3}$ Department of Social and Preventive Medicine, Laval University, Quebec City, QC, Canada. ${ }^{4}$ Pathology Laboratory, St-Sacrement Hospital, CHU de Quebec-Laval University, Quebec City, QC, Canada.

\section{Acknowledgements}

The authors thank the participants and their families for their generosity and providing samples. The authors also thank N. Paquet involved in qRT-PCR experiments, K.V. Plourde for RNA extraction from breast adipose tissue, M. Pelletier for her help regarding thin-layer chromatography technique and $\mathrm{M}$. Verreault regarding omega experiments.

\section{Competing interests}

The authors declare that they have no competing interests.

\section{Availability of data and materials}

All data generated and analysed during this study are included in this published article.

\section{Consent for publication}

Not applicable.

\section{Ethics approval and consent to participate}

The study protocol was reviewed and approved by the Research ethics committee of the Centre de Recherche du CHU de Québec-Laval University, in accordance with their relevant guidelines and regulations.

\section{Funding}

This work was supported by grants from the Canadian Cancer Society Research Institute, the Canadian Breast Cancer Research Alliance (Grant \#20462), the Réseau de recherche en santé cardiométabolique, diabète et obésité (Grant \#314074) of the "Fond de recherche du Québec - Santé (FRQS)" and the "Banque de tissus et données of the Réseau de recherche sur le cancer" of the "Fondation du cancer du sein du Québec" and the FRQS associated with the Canadian Tumor Repository Network (CTRNet). FAS holds a studentship from Fondation René Bussières. KEl holds a bourse d'études supérieures du Canada Vanier (BESC Vanier) from IRSC. CD is a senior Research Scholar from the FRSQ.

\section{Publisher's Note}

Springer Nature remains neutral with regard to jurisdictional claims in published maps and institutional affiliations.

Received: 28 July 2018 Accepted: 11 October 2018

Published online: 22 October 2018

\section{References}

1. Ferlay J, Soerjomataram I, Dikshit R, Eser S, Mathers C, Rebelo M, et al. Cancer incidence and mortality worldwide: sources, methods and major patterns in GLOBOCAN 2012. Int J Cancer. 2015;136(5):E359-86.

2. Colotta F, Allavena P, Sica A, Garlanda C, Mantovani A. Cancer-related inflammation, the seventh hallmark of cancer: links to genetic instability. Carcinogenesis. 2009;30(7):1073-81.

3. Jiang $X$, Shapiro DJ. The immune system and inflammation in breast cancer. Mol Cell Endocrinol. 2014;382(1):673-82.

4. Freeman MR, Li Q, Chung LW. Can stroma reaction predict cancer lethality? Clin Cancer Res. 2013;19(18):4905-7.

5. Klintrup K, Makinen JM, Kauppila S, Vare PO, Melkko J, Tuominen H, et al. Inflammation and prognosis in colorectal cancer. Eur J Cancer. 2005;41(17):2645-54.

6. Mohammed ZM, Going JJ, Edwards J, Elsberger B, McMillan DC. The relationship between lymphocyte subsets and clinico-pathological determinants of survival in patients with primary operable invasive ductal breast cancer. Br J Cancer. 2013;109(6):1676-84.

7. Richards CH, Flegg KM, Roxburgh CS, Going JJ, Mohammed Z, Horgan $P G$, et al. The relationships between cellular components of the peritumoural inflammatory response, clinicopathological characteristics and survival in patients with primary operable colorectal cancer. Br J Cancer. 2012;106(12):2010-5.

8. Salgado R, Denkert C, Demaria S, Sirtaine N, Klauschen F, Pruneri G, et al. The evaluation of tumor-infiltrating lymphocytes (TILs) in breast cancer: recommendations by an International TILs Working Group 2014. Ann Oncol. 2015;26(2):259-71.

9. Tang X. Tumor-associated macrophages as potential diagnostic and prognostic biomarkers in breast cancer. Cancer Lett. 2013;332(1):3-10.

10. Tricot G. New insights into role of microenvironment in multiple myeloma. Lancet. 2000;355(9200):248-50.

11. Utans U, Arceci RJ, Yamashita Y, Russell ME. Cloning and characterization of allograft inflammatory factor-1: a novel macrophage factor identified in rat cardiac allografts with chronic rejection. J Clin Invest. 1995:95(6):2954-62.

12. Deininger $M H$, Meyermann R, Schluesener HJ. The allograft inflammatory factor-1 family of proteins. FEBS Lett. 2002;514(2-3):115-21. 
13. Zhao YY, Yan DJ, Chen ZW. Role of AIF-1 in the regulation of inflammatory activation and diverse disease processes. Cell Immunol. 2013;284(1-2):75-83.

14. Fukui M, Tanaka M, Toda H, Asano M, Yamazaki M, Hasegawa G, et al The serum concentration of allograft inflammatory factor-1 is correlated with metabolic parameters in healthy subjects. Metabolism. 2012;61(7):1021-5.

15. Lorente-Cebrian S, Decaunes P, Dungner E, Bouloumie A, Arner P, Dahlman I. Allograft inflammatory factor 1 (AIF-1) is a new human adipokine involved in adipose inflammation in obese women. BMC Endocr Disord. 2013:13:54

16. Fukui M, Tanaka M, Asano M, Yamazaki M, Hasegawa G, Imai S, et al. Serum allograft inflammatory factor-1 is a novel marker for diabetic nephropathy. Diabetes Res Clin Pract. 2012;97(1):146-50.

17. Huang $X$, Zhao Y, Jia S, Yan D, Chen Z. Effects of daintain/AlF-1 on beta cell dysfunction in INS-1 cells. Biosci Biotechnol Biochem. 2011;75(9):1842-4.

18. Zhao YY, Huang XY, Chen ZW. Daintain/AIF-1 (allograft inflammatory factor-1) accelerates type 1 diabetes in NOD mice. Biochem Biophys Res Commun. 2012:427(3):513-7.

19. Deininger MH, Seid K, Engel S, Meyermann R, Schluesener HJ. Allograft inflammatory factor-1 defines a distinct subset of infiltrating macrophages/microglial cells in rat and human gliomas. Acta Neuropathol. 2000:100(6):673-80.

20. Jia J, Bai Y, Fu K, Sun ZJ, Chen XM, Zhao YF. Expression of allograft inflammatory factor-1 and CD68 in haemangioma: implication in the progression of haemangioma. Br J Dermatol. 2008;159(4):811-9.

21. Tian Y, Kelemen SE, Autieri MV. Inhibition of AlF-1 expression by constitutive siRNA expression reduces macrophage migration, proliferation, and signal transduction initiated by atherogenic stimuli. Am J Physiol Cell Physiol. 2006;290(4):C1083-91.

22. Watano K, Iwabuchi K, Fujii S, Ishimori N, Mitsuhashi S, Ato M, et al. Allograft inflammatory factor-1 augments production of interleukin-6, -10 and -12 by a mouse macrophage line. Immunology. 2001;104(3):307-16.

23. Khirade MF, Lal G, Bapat SA. Derivation of a fifteen gene prognostic panel for six cancers. Sci Rep. 2015:5:13248.

24. Jia J, Cai Y, Wang R, Fu K, Zhao YF. Overexpression of allograft inflammatory factor-1 promotes the proliferation and migration of human endothelial cells (HUV-EC-C) probably by up-regulation of basic fibroblast growth factor. Pediatr Res. 2010;67(1):29-34.

25. Liu S, Tan WY, Chen QR, Chen XP, Fu K, Zhao YY, et al. Daintain/AIF-1 promotes breast cancer proliferation via activation of the NF-kappaB/cyclin D1 pathway and facilitates tumor growth. Cancer Sci. 2008;99(5):952-7.

26. Li T, Feng Z, Jia S, Wang W, Du Z, Chen N, et al. Daintain/AlF-1 promotes breast cancer cell migration by up-regulated TNF-alpha via activate p38 MAPK signaling pathway. Breast Cancer Res Treat. 2012;131(3):891-8.

27. Jia S, Chaibou MA, Chen Z. Daintain/AIF-1 reinforces the resistance of breast cancer cells to cisplatin. Biosci Biotechnol Biochem. 2012:76(12):2338-41.

28. Pouliot MC, Kothari C, Joly-Beauparlant C, Labrie Y, Ouellette G, Simard $J$, et al. Transcriptional signature of lymphoblastoid cell lines of BRCA1, BRCA2 and non-BRCA1/2 high risk breast cancer families. Oncotarget. 2017:8(45):78691-712

29. Ennour-Idrissi K, Tetu B, Maunsell E, Poirier B, Montoni A, Rochette PJ, et al. Association of telomere length with breast cancer prognostic factors. PLOS ONE. 2016;11(8):e0161903.

30. Genin M, Clement F, Fattaccioli A, Raes M, Michiels C. M1 and M2 macrophages derived from THP-1 cells differentially modulate the response of cancer cells to etoposide. BMC Cancer. 2015;15:577.

31. Pfaffl MW. A new mathematical model for relative quantification in realtime RT-PCR. Nucleic Acids Res. 2001;29(9):e45.

32. Warrington JA, Nair A, Mahadevappa M, Tsyganskaya M. Comparison of human adult and fetal expression and identification of 535 housekeeping/maintenance genes. Physiol Genomics. 2000;2(3):143-7.

33. Bustin SA, Beaulieu JF, Huggett J, Jaggi R, Kibenge FS, Olsvik PA, et al. MIQE precis: practical implementation of minimum standard guidelines for fluorescence-based quantitative real-time PCR experiments. BMC Mol Biol. 2010;11:74

34. Bustin SA, Benes V, Garson JA, Hellemans J, Huggett J, Kubista M, et al. The MIQE guidelines: minimum information for publication of quantitative real-time PCR experiments. Clin Chem. 2009:55(4):611-22.
35. Park JH, McMillan DC, Edwards J, Horgan PG, Roxburgh CS. Comparison of the prognostic value of measures of the tumor inflammatory cell infiltrate and tumor-associated stroma in patients with primary operable colorectal cancer. Oncoimmunology. 2016;5(3):e1098801.

36. Soguel $\mathrm{L}$, Diorio $C$. Anthropometric factors, adult weight gain, and mammographic features. Cancer Causes Control. 2016;27(3):333-40.

37. Markham NR, Zuker M. DINAMelt web server for nucleic acid melting prediction. Nucleic Acids Res. 2005;33(Web Server issue):W577-81.

38. Larkin MA, Blackshields G, Brown NP, Chenna R, McGettigan PA, McWilliam H, et al. Clustal W and Clustal X version 2.0. Bioinformatics. 2007;23(21):2947-8.

39. Yang J, Zhang Y. Protein structure and function prediction using I-TASSER. Curr Protoc Bioinformatics. 2015;52:5-8.

40. Fidler TP, Campbell RA, Funari T, Dunne N, Balderas Angeles E, Middleton EA, et al. Deletion of GLUT1 and GLUT3 reveals multiple roles for glucose metabolism in platelet and megakaryocyte function. Cell Rep. 2017;20(4):881-94.

41. Lal I, Dittus K, Holmes CE. Platelets, coagulation and fibrinolysis in breast cancer progression. Breast Cancer Res. 2013;15(4):207.

42. Calder PC. Omega-3 fatty acids and inflammatory processes. Nutrients. 2010;2(3):355-74.

43. Autieri MV. cDNA cloning of human allograft inflammatory factor-1: tissue distribution, cytokine induction, and mRNA expression in injured rat carotid arteries. Biochem Biophys Res Commun. 1996;228(1):29-37.

44. Del Galdo F, Jimenez SA. T cells expressing allograft inflammatory factor 1 display increased chemotaxis and induce a profibrotic phenotype in normal fibroblasts in vitro. Arthritis Rheum. 2007:56(10):3478-88.

45. Schwab JM, Frei E, Klusman I, Schnell L, Schwab ME, Schluesener HJ. AIF-1 expression defines a proliferating and alert microglial/macrophage phenotype following spinal cord injury in rats. J Neuroimmunol. 2001:119(2):214-22.

46. Chanmee T, Ontong P, Konno K, Itano N. Tumor-associated macrophages as major players in the tumor microenvironment. Cancers. 2014;6(3):1670-90.

47. Grivennikov SI, Greten FR, Karin M. Immunity, inflammation, and cancer. Cell. 2010;140(6):883-99.

48. Cai H, Zhu XD, Ao JY, Ye BG, Zhang YY, Chai ZT, et al. Colony-stimulating factor-1-induced AIF1 expression in tumor-associated macrophages enhances the progression of hepatocellular carcinoma. Oncoimmunology. 2017;6(9):e1333213.

49. Li X, Yao W, Yuan Y, Chen P, Li B, Li J, et al. Targeting of tumour-infiltrating macrophages via CCL2/CCR2 signalling as a therapeutic strategy against hepatocellular carcinoma. Gut. 2017;66(1):157-67.

50. Hussein MR, Elsers DA, Fadel SA, Omar AE. Immunohistological characterisation of tumour infiltrating lymphocytes in melanocytic skin lesions. J Clin Pathol. 2006:59(3):316-24.

51. Tan AH, Goh SY, Wong SC, Lam KP. T helper cell-specific regulation of inducible costimulator expression via distinct mechanisms mediated by T-bet and GATA-3. J Biol Chem. 2008;283(1):128-36.

52. Zitvogel L, Galluzzi L, Kepp O, Smyth MJ, Kroemer G. Type I interferons in anticancer immunity. Nat Rev Immunol. 2015;15(7):405-14.

53. Mohammed ZM, Going JJ, Edwards J, McMillan DC. The role of the tumour inflammatory cell infiltrate in predicting recurrence and survival in patients with primary operable breast cancer. Cancer Treat Rev. 2012;38(8):943-55.

54. Bremnes RM, Busund LT, Kilvaer TL, Andersen S, Richardsen E, Paulsen $\mathrm{EE}$, et al. The role of tumor-infiltrating lymphocytes in development, progression, and prognosis of non-small cell lung cancer. J Thorac Oncol. 2016;11(6):789-800.

55. Roxburgh CS, Salmond JM, Horgan PG, Oien KA, McMillan DC. Tumour inflammatory infiltrate predicts survival following curative resection for node-negative colorectal cancer. Eur J Cancer. 2009;45(12):2138-45.

56. Fox HS, Bond BL, Parslow TG. Estrogen regulates the IFN-gamma promoter. J Immunol. 1991;146(12):4362-7.

57. Leek RD, Landers RJ, Harris AL, Lewis CE. Necrosis correlates with high vascular density and focal macrophage infiltration in invasive carcinoma of the breast. Br J Cancer. 1999;79(5-6):991-5.

58. Nakaya M, Tachibana H, Yamada K. Effect of estrogens on the interferongamma producing cell population of mouse splenocytes. Biosci Biotechnol Biochem. 2006;70(1):47-53. 
59. Ruh MF, Bi Y, D'Alonzo R, Bellone CJ. Effect of estrogens on IL-1 beta promoter activity. J Steroid Biochem Mol Biol. 1998;66(4):203-10.

60. Yan DJ, Chen ZW. 17beta-Estradiol increased the expression of daintain/AIF-1 in RAW264.7 macrophages. Biosci Biotechnol Biochem. 2010;74(10):2103-5.

61. Schley PD, Jijon HB, Robinson LE, Field CJ. Mechanisms of omega-3 fatty acid-induced growth inhibition in MDA-MB-231 human breast cancer cells. Breast Cancer Res Treat. 2005;92(2):187-95.

62. Liu J, Ma DW. The role of n-3 polyunsaturated fatty acids in the prevention and treatment of breast cancer. Nutrients. 2014;6(11):5184-223.
63. Merendino N, Costantini L, Manzi L, Molinari R, D'Eliseo D, Velotti F. Dietary omega-3 polyunsaturated fatty acid DHA: a potential adjuvant in the treatment of cancer. Biomed Res Int. 2013;2013:310186.

64. Vaughan VC, Hassing MR, Lewandowski PA. Marine polyunsaturated fatty acids and cancer therapy. Br J Cancer. 2013;108(3):486-92.

65. Monk JM, Turk HF, Liddle DM, De Boer AA, Power KA, Ma DW, et al. n-3 polyunsaturated fatty acids and mechanisms to mitigate inflammatory paracrine signaling in obesity-associated breast cancer. Nutrients. 2014;6(11):4760-93
Ready to submit your research? Choose BMC and benefit from:

- fast, convenient online submission

- thorough peer review by experienced researchers in your field

- rapid publication on acceptance

- support for research data, including large and complex data types

- gold Open Access which fosters wider collaboration and increased citations

- maximum visibility for your research: over $100 \mathrm{M}$ website views per year

At BMC, research is always in progress.

Learn more biomedcentral.com/submissions 